\title{
Frequency of Neurologic Manifestations in COVID-19
}

\author{
A Systematic Review and Meta-analysis
}

Shubham Misra, MTech, Kavitha Kolappa, MD, Manya Prasad, MD, Divya Radhakrishnan, DM, Kiran T. Thakur, MD, Tom Solomon, FRCP, Benedict Daniel Michael, PhD, Andrea Sylvia Winkler, PhD, Ettore Beghi, MD, Alla Guekht, MD, Carlos A. Pardo, MD, Greta Karen Wood, MRes, Sherry Hsiang-Yi Chou, MD, Ericka L. Fink, MD, Erich Schmutzhard, MD, Amir Kheradmand, MD, Fan Kee Hoo, MD, Amit Kumar, PhD, Animesh Das, DM, Achal K. Srivastava, DM, Ayush Agarwal, DM, Tarun Dua, MD, and Kameshwar Prasad, DM

Neurology ${ }^{\circledR}$ 2021;97:e2269-e2281. doi:10.1212/WNL.0000000000012930

\section{Abstract}

\section{Background and objectives}

One year after the onset of the coronavirus disease 2019 (COVID-19) pandemic, we aimed to summarize the frequency of neurologic manifestations reported in patients with COVID-19 and to investigate the association of these manifestations with disease severity and mortality.

\section{Methods}

We searched PubMed, Medline, Cochrane library, ClinicalTrials.gov, and EMBASE for studies from December 31, 2019, to December 15, 2020, enrolling consecutive patients with COVID19 presenting with neurologic manifestations. Risk of bias was examined with the Joanna Briggs Institute scale. A random-effects meta-analysis was performed, and pooled prevalence and 95\% confidence intervals (CIs) were calculated for neurologic manifestations. Odds ratio (ORs) and 95\% CIs were calculated to determine the association of neurologic manifestations with disease severity and mortality. Presence of heterogeneity was assessed with $I^{2}$, meta-regression, and subgroup analyses. Statistical analyses were conducted in $\mathrm{R}$ version 3.6.2.

\section{Results}

Of 2,455 citations, 350 studies were included in this review, providing data on 145,721 patients with COVID-19, 89\% of whom were hospitalized. Forty-one neurologic manifestations (24 symptoms and 17 diagnoses) were identified. Pooled prevalence of the most common neurologic symptoms included fatigue (32\%), myalgia (20\%), taste impairment (21\%), smell impairment (19\%), and headache (13\%). A low risk of bias was observed in $85 \%$ of studies; studies with higher risk of bias yielded higher prevalence estimates. Stroke was the most common neurologic diagnosis (pooled prevalence 2\%). In patients with COVID-19 $\geq 60$ years of age, the pooled prevalence of acute confusion/delirium was $34 \%$, and the presence of any neurologic manifestations in this age group was associated with mortality (OR 1.80, 95\% CI 1.11-2.91).

\section{Discussion}

Up to one-third of patients with COVID-19 analyzed in this review experienced at least 1 neurologic manifestation. One in 50 patients experienced stroke. In those $>60$ years of age, more than one-third had acute confusion/delirium; the presence of neurologic manifestations in this group was associated with nearly a doubling of mortality. Results must be interpreted with the limitations of observational studies and associated bias in mind.

\author{
Correspondence \\ Dr. Prasad \\ drkameshwarprasad@ \\ gmail.com
}

\section{MORE ONLINE}

COVID-19 Resources

For the latest articles, invited commentaries, and blogs from physicians around the world NPub.org/COVID19

\footnotetext{
From the Department of Neurology (S.M., D.R., A.K., A.D., A.K.S., A.A.), All India Institute of Medical Sciences, New Delhi, India; Brain Health Unit (K.K., T.D.), World Health Organization, Geneva, Switzerland; Department of Clinical Research and Epidemiology (M.P.), Institute of Liver and Biliary Sciences, New Delhi, India; Columbia University Irving Medical Center-New York Presbyterian Hospital (K.T.T.), NY; Institute of Infection, Veterinary and Ecological Sciences (T.S., B.D.M., G.K.W.), University of Liverpool; Department of Neurology (T.S., B.D.M.), Walton Centre NHS Foundation Trust; NIHR Health Protection Research Unit for Emerging and Zoonotic Infection (B.D.M.), Liverpool, UK; Center for Global Health (A.S.W.), Department of Neurology, Technical University of Munich, Germany; Centre for Global Health (A.S.W.), Institute of Health and Society, University of Oslo, Norway; Istituto di Ricerche Farmacologiche Mario Negri IRCCS (E.B.), Milan, Italy; Moscow Research and Clinical Center for Neuropsychiatry and Pirogov Russian National Research Medical University (A.G.), Russia; Departments of Neurology and Pathology (C.A.P.), Johns Hopkins University School of Medicine, Baltimore, MD; University of Pittsburgh School of Medicine (S.H.-Y.C.); Department of Critical Care Medicine (E.L.F.), UPMC Children's Hospital of Pittsburgh, PA; Department of Neurology (E.S.), Medical University Innsbruck, Austria; Departments of Neurology and Otolaryngology-Head \& Neck Surgery (A.K.), The Johns Hopkins Hospital, Baltimore, MD; Department of Neurology (F.K.H.), Faculty of Medicine and Health Sciences, University Putra Malaysia, Seri Kembangan; and Rajendra Institute of Medical Sciences (K.P.), Ranchi, Jharkhand, India.

Go to Neurology.org/N for full disclosures. Funding information and disclosures deemed relevant by the authors, if any, are provided at the end of the article.
} 


\section{Glossary}

CI = confidence interval; COVID-19 = coronavirus disease 2019; OR = odds ratio; SARS-CoV-2 = severe acute respiratory syndrome coronavirus 2; WHO = World Health Organization .

\section{Systematic Review Registration PROSPERO CRD42020181867.}

One year into the coronavirus disease 2019 (COVID-19) pandemic, the disease caused by the severe acute respiratory syndrome coronavirus 2 (SARS-CoV-2) has left nearly no place on Earth untouched, with $>202$ million confirmed cases and 4.28 million deaths across 220 countries and territories up to August 9, 2021. ${ }^{1}$ The disease spectrum has ranged from asymptomatic cases with or without mild respiratory symptoms to severe cases with respiratory failure and multiorgan dysfunction. ${ }^{2-4}$ Over the past year, reports of neurologic manifestations associated with COVID-19 have increased rapidly, with the CNS, peripheral nervous system, and musculoskeletal system affected. ${ }^{5-7}$ The World Health Organization (WHO) has recognized the clinical relevance of neurologic manifestations of COVID-19.,

Prior systematic reviews have highlighted the frequency of common neurologic symptoms observed in COVID-19, including fatigue, myalgia, impaired sense of smell or taste, and headaches. ${ }^{10-12}$ Additional neurologic manifestations reported include dizziness, acute confusion/delirium, agitation, stroke, hypoxic ischemic injury, seizures, coma, and encephalitis, among others. ${ }^{11,12}$ In some cases, neurologic manifestations have been reported even without respiratory symptoms. ${ }^{13-15}$ However, considerable variations in the frequency of neurologic manifestations have been reported with respect to different ethnic populations, age, and hospitalization status of included patients, and severity of disease. ${ }^{12}$ Reports of neurologic manifestations in patients with COVID-19 are accumulating rapidly, and this warrants updated meta-analyses with pooled prevalence estimates. In addition, questions remain as to whether the presence of neurologic manifestations is associated with increased mortality, as initial reports have suggested. ${ }^{16}$

We conducted a systematic review and meta-analysis to obtain pooled prevalence estimates and to understand the variations in the reported frequencies of various neurologic manifestations (including symptoms and diagnoses) in patients with COVID19 across different age groups. This review updates the findings of the previously published systematic reviews on neurologic symptoms, explores the reasons for heterogeneity of published studies, and gives novel insights into the pooled prevalence of neurologic diagnoses in patients with COVID-19. Our review further investigates the association of neurologic manifestations with COVID-19 severity and mortality.

\section{Methods}

\section{Literature Search}

Our intention was to cover a 1-year period to reflect on the cumulative knowledge about neurologic manifestations seen in COVID-19. A comprehensive literature search was carried out by 5 authors (S.M., D.R., K.T.T., A.K., and A.D.) for the period of December 31, 2019, to December 15, 2020, in PubMed, EMBASE, MEDLINE, Google Scholar, Cochrane Library and ClinicalTrials.gov. The detailed search strategy is provided in eAppendix 1 (links.lww.com/WNL/B607).

\section{Population}

The target population for this review includes patients clinically suspected to have COVID-19 confirmed by real-time reversetranscription PCR detection, high-throughput sequencing, SARS-CoV-2 viral culture in throat swab specimens, or SARS$\mathrm{CoV}-2$ antibody detection in blood samples. Studies had to report $\geq 1$ new-onset neurologic manifestation(s) in a proportion of the included patients temporally associated with SARS-CoV-2 infection and not explained by an alternate etiology. We also included studies reporting probable cases of COVID-19, according to WHO case definitions, ${ }^{17}$ based on clinical presentation when diagnostic testing was not available.

\section{Intervention}

None.

\section{Comparator}

The main objective of this review (describing the frequency of neurologic manifestations) did not merit a comparator group; however, for the secondary objectives of determining whether neurologic manifestations were associated with severity or mortality, the events were compared between patients with severe and nonsevere COVID-19 and between those with and without neurologic manifestations.

\section{Outcomes}

The primary outcome was the frequency of neurologic manifestations in patients with COVID-19. Considering the lack of uniformity and reporting regarding classifications, definitions, and diagnostic criteria of neurologic manifestations across studies, we decided to accept study definitions as reported. For calculating pooled prevalence, both the numerator (number with neurologic manifestations) and denominator (total number of patients with COVID-19 attending the facility) were required. 
Studies without the denominator were not included in the metaanalysis and are listed in eTables 1 and 2 (links.lww.com/WNL/ B607). Secondary outcomes included age-specific variations in neurologic manifestations and association of neurologic manifestations with severity of and mortality in COVID-19.

\section{Inclusion and Exclusion Criteria}

Our systematic review and meta-analysis was conducted according to the Preferred Reporting Items for Systematic Reviews and Meta-Analyses Protocol 2015 guidelines ${ }^{18}$ (checklist provided in supplemental material) and included observational studies on humans that (1) included individuals with probable or confirmed COVID-19 defined as above, (2) reported neurologic manifestations, (3) had full texts available, and (4) were published in indexed journals. There were no restrictions on language.

Studies meeting the above inclusion criteria were excluded if either of the following applied: they did not specify inclusion of consecutive patients with COVID-19 or they were individual case reports, or reviews, narratives, or editorials. The protocol of this systematic review and meta-analysis was registered in PROSPERO (registration CRD42020181867), and there were no major deviations from the protocol. ${ }^{19}$

\section{Data Extraction}

Two authors (S.M. and D.R.) independently screened titles and abstracts retrieved by the literature search against the eligibility criteria. Duplicate records were excluded. The following information was extracted from each eligible study: first author; year of publication; study design; sample size; mean or median age of participants; comorbid conditions; clinical parameters; severity of COVID-19 infection; neurologic symptoms; and diagnoses. Hospitalization status of patients with COVID-19 was extracted independently by 2 authors. The definitions are given in eAppendix 2 (links.lww.com/WNL/B607), and interrater agreements are shown in eTables 3 and 4. Any disagreement between the reviewers was settled by consensus or by referring to a third author.

\section{Risk of Bias Assessment}

To choose a tool for assessing risk of bias, 5 available tools were critically evaluated for coverage of selection and measurement bias, clarity of wording, suitability for descriptive case series, and ease of use. The Joanna Briggs Institute tool was selected, and risk of bias assessment was conducted by 5 authors (S.M., D.R, K.T.T., A.K., and A.D.) for all studies included in this review. ${ }^{20}$

\section{Statistical Analysis}

Age was represented by mean with SD, whereas sex was represented by number with percentages. Meta-analyses were performed if data on the frequency of a specified neurologic manifestation were available from $\geq 2$ or studies. Pooled prevalence for each neurologic manifestation, along with its corresponding 95\% confidence interval (CI), was calculated with a random-effects model. For pooling, prevalence estimates were transformed with the Freeman-Tukey double arcsine transformation for better approximation to normal distribution as required by the assumption of conventional meta-analytic model. ${ }^{21}$ The associations between neurologic symptoms and both severity of and mortality in COVID-19 were determined with the odds ratio (OR) and 95\% CI. Subgroup analyses were also conducted to estimate the pooled prevalence of neurologic symptoms and diagnoses in the elderly and young populations. The false discovery rate was controlled with the BenjaminiHochberg procedure. The presence of heterogeneity was assessed with $I^{2}$. Funnel plots were used to assess the risk of publication bias. The Egger regression test ${ }^{22}$ was used to quantitatively assess the funnel plot asymmetry, with a value of $p<0.05$ indicating the possibility of publication bias. The trim-and-fill test of Duval and Tweedie ${ }^{23}$ was then used to impute the missing studies into the funnel plots until symmetry was achieved.

A meta-regression analysis was performed to further explore the source of heterogeneity for neurologic symptoms and diagnoses wherein $\geq 10$ studies were pooled. If risk of bias was found to be significantly associated with prevalence, then a subgroup analysis was conducted to stratify the outcome variables in terms of low, moderate, and high risk of bias. Values of $p<0.05$ were considered to be statistically significant. Statistical analyses were conducted in $\mathrm{R}$ version 3.6.2 ( $\mathrm{R}$ Foundation for Statistical Computing, Vienna, Austria). ${ }^{24}$

\section{Data Availability}

The full dataset and statistical codes will be available on reasonable request from any qualified investigator.

\section{Results}

Our search yielded 2,455 articles, of which 778 were screened by full text; 350 met the inclusion criteria and were included in our systematic review and meta-analysis (Figure 1). Of the 350 studies, 15 were included from non-English languages, for which the online English versions were retrieved. Twenty studies included only young patients with COVID-19 (age $<18$ years), while 14 studies included only elderly patients (age $\geq 60$ years). The studies included data from 55 countries. Baseline characteristics of all the studies included in this systematic review and meta-analysis are provided in eTables 5 and 6 (links. lww.com/WNL/B607) (including countries classified by World Bank Income Category and WHO regions). The pictorial representation of the coverage of studies from different parts of the world included in our systematic review and metaanalysis is given in eFigure 1 . The included studies were published between January 2020 and December 2020.

A total of 145,721 cases with COVID-19 (mean 416.34, median 120, IQR 62-299, range 8-15,111) were analyzed in our systematic review, including $51 \%$ males. Hospitalization was reported for 129,786 cases (89\%); 9,188 cases (6\%) were not hospitalized, and hospitalization status was not reported for 6,747 (5\%). Preexisting medical comorbid conditions were reported for hypertension (26\%, 95\% CI 24\%-28\%); diabetes (14\%, 95\% CI 13\%-15\%); cardiovascular/ 


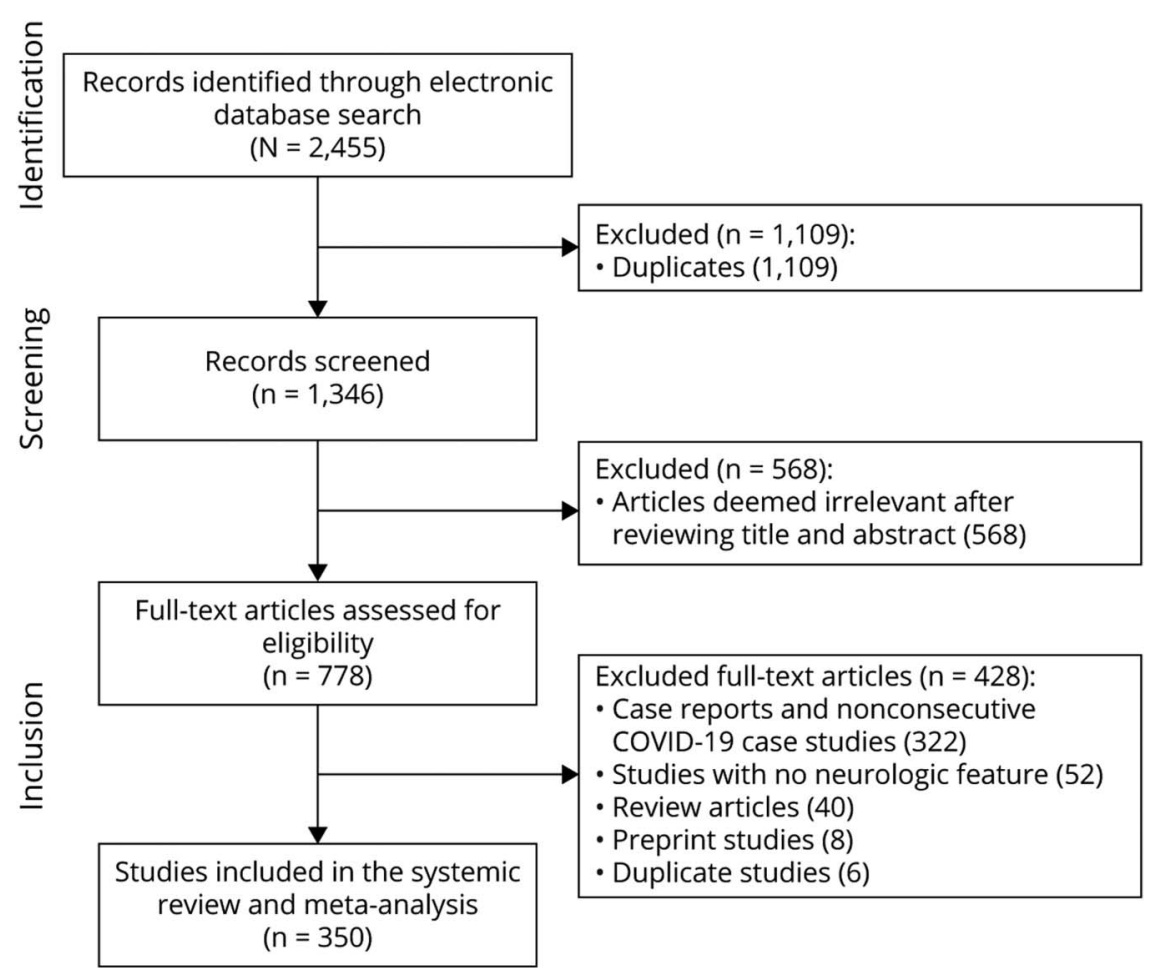

COVID-19 = coronavirus disease 2019; PRISMA = Preferred Reporting Items for Systematic Reviews and Meta-Analyses. cerebrovascular disease (aggregated reporting) (18\%, 95\% CI $12 \%-23 \%)$; cardiovascular disease (10\%, 95\% CI 9\%-11\%); chronic obstructive pulmonary disease (5\%, 95\% CI 4\%-6\%); chronic kidney disease (5\%, 95\% CI 4\%-5\%); cerebrovascular disease (4\%, 95\% CI 3\%-4\%); malignancy (4\%, 95\% CI $3 \%-4 \%)$; and chronic liver disease (3\%, 95\% CI 3\%-4\%).

Individual case reports and case series including neurologic manifestations in nonconsecutive cases of COVID-19 or a specific subgroup of cases of COVID-19 were present in an additional 322 studies detailed in eTables 1 and 2 (links.lww. com/WNL/B607).

\section{Risk of Bias Assessment}

Risk of bias scores assessed with the Joanna Briggs Institute tool were categorized into low (13-16), moderate (7-12), and high (0-6). Overall, 296 studies (84.6\%) had a low risk of bias, 49 studies (14\%) had a moderate risk, and 5 studies (1.4\%) had a high risk. eTable 7 (links.lww.com/WNL/ B607) represents the risk of bias assessment done for studies included in our systematic review and meta-analysis.

\section{Neurologic Manifestations in Patients With COVID-19}

Twenty-four neurologic symptoms from 305 articles are included in our systematic review and meta-analysis. Pooled prevalences (95\% CI, number of studies) of the most common neurologic symptoms include the following: fatigue $32 \%$ (95\% CI 30\%-35\%, 169 studies); myalgia 20\% (95\% CI
$18 \%-23 \%, 207$ studies); myalgia or fatigue $31 \%$ (95\% CI $25 \%-37 \%$, 22 studies); headache 13\% (95\% CI 12\%-15\%, 202 studies); dizziness 7\% (95\% CI 5\%-8\%, 46 studies); headache and dizziness together 12\% (95\% CI 8\%-17\%, 9 studies); smell impairment 19\% (95\% CI 13\%-25\%, 51 studies); taste impairment 21\% (95\% CI 15\%-29\%, 38 studies); smell or taste impairment 18\% (95\% CI 10\%-28\%, 14 studies); acute confusion/delirium 11\% (95\% CI 7\%-16\%, 19 studies); disturbance of consciousness 7\% (95\% CI 5\%-10\%, 25 studies); and agitation 45\% (95\% CI 3\%-93\%, 3 studies). Pooled prevalences of neurologic symptoms included in the meta-analysis are given in Table 1, including the individual prevalence of neurologic symptoms for which meta-analyses were not possible.

Seventeen different neurologic diagnoses in patients with COVID-19 were observed in 33 studies. The highest number of studies $(n=29)$ were pooled for stroke with a pooled prevalence of $2 \%$ (95\% CI 1\%-2\%) (Figure 2). Acute cerebrovascular events were categorized into ischemic stroke or TIA in 1\% (95\% CI 1\%-2\%, 29 studies), hemorrhagic stroke in $0.31 \%$ (95\% CI $0.15 \%-0.50 \%, 21$ studies), and cerebral venous thrombosis in $0.12 \%$ (95\% CI 0\%-2\%, 2 studies). The pooled prevalence of neuropsychiatric disorders was $24 \%$ (95\% CI 2\%-61\%, 3 studies) and that of skeletal muscle injury was $5 \%$ (95\% CI 1\%-12\%, 4 studies). Pooled prevalences of neurologic diagnoses included in the meta-analysis are given in Table 2, including the individual prevalence of various neurologic diagnoses for which meta-analyses were not possible. 
Table 1 Prevalence of Various Neurologic Symptoms Included in the Systematic Review and Meta-analysis

\begin{tabular}{|c|c|c|c|c|c|c|}
\hline Study & Variables & Studies, $\mathrm{n}$ & Pooled events, $n$ & Pooled sample size, $n$ & Pooled prevalence $(95 \% \mathrm{CI}), \%$ & $I^{2}$ value, $\%$ \\
\hline 1 & Myalgia & 207 & 12,183 & 59,821 & $20(18-23)$ & 97 \\
\hline 2 & Fatigue & 169 & 14,121 & 45,766 & $32(30-35)$ & 97 \\
\hline 3 & Myalgia or fatigue $^{a}$ & 22 & 619 & 2,246 & $31(25-37)$ & 89 \\
\hline 4 & Headache & 202 & 8,609 & 51,969 & $13(12-15)$ & 98 \\
\hline 5 & Dizziness & 46 & 809 & 13,473 & $7(5-8)$ & 91 \\
\hline 6 & Headache and dizziness $^{a}$ & 9 & 676 & 3,520 & $12(8-17)$ & 88 \\
\hline 7 & Smell impairment & 51 & 4,647 & 30,925 & $19(13-25)$ & 99 \\
\hline 8 & Taste impairment & 38 & 2,934 & 12,631 & $21(15-29)$ & 99 \\
\hline 9 & Smell or taste impairment ${ }^{a}$ & 14 & 518 & 3,100 & $18(10-28)$ & 97 \\
\hline 10 & Acute confusion/delirium & 19 & 2,318 & 23,921 & $11(7-16)$ & 99 \\
\hline 11 & Disturbance of consciousness & 25 & 693 & 15,129 & $7(5-10)$ & 97 \\
\hline 12 & Seizure & 15 & 127 & 15,467 & $1(0-2)$ & 90 \\
\hline 13 & Ataxia & 5 & 25 & 2,266 & $1(0-2)$ & 89 \\
\hline 14 & Vision impairment & 10 & 126 & 2,904 & $4(1-9)$ & 95 \\
\hline 15 & Hearing impairment & 6 & 20 & 819 & $3(1-5)$ & 54 \\
\hline 16 & Sensory impairment & 4 & 23 & 1,082 & $2(1-5)$ & 81 \\
\hline 17 & Cognitive impairment & 3 & 22 & 1,131 & $2(0-5)$ & 83 \\
\hline 18 & Neuralgia & 7 & 41 & 3,183 & $1(0-3)$ & 90 \\
\hline 19 & Tinnitus & 5 & 30 & 884 & $5(1-10)$ & 88 \\
\hline 20 & Agitation & 3 & 145 & 468 & $45(3-93)$ & 99 \\
\hline 21 & CN palsy & 3 & 7 & 463 & $2(0-8)$ & 75 \\
\hline 22 & Hemiplegia/hemiparesis & 2 & 5 & 467 & $2(0-10)$ & 88 \\
\hline 23 & Corticospinal tract signs & 2 & 128 & 198 & $65(58-71)$ & 0 \\
\hline 24 & Language impairment & 1 & 6 & 38 & $16(6-31)$ & - \\
\hline
\end{tabular}

Abbreviations: $\mathrm{Cl}=$ confidence interval; $\mathrm{CN}=$ cranial nerve.

a These studies did not separate myalgia from fatigue, headache from dizziness, and smell from taste impairment.

\section{Neurologic Manifestations and Severity of COVID-19}

Forty-eight studies consisting of 2,829 severe cases (classified as either severe or critical) and 7,493 nonsevere cases (classified as either mild or moderate) were analyzed to determine the association between neurologic manifestations and severity of COVID-19. Skeletal muscle injury/damage in 2 studies (OR 3.29, 95\% CI 2.15-5.04), disturbance of consciousness (OR 5.68, 95\% CI 2.08-15.50) in 4 studies, and fatigue in 33 studies (OR 1.27, 95\% CI 1.06-1.51) were significantly associated with severe COVID-19.

Patients with severe COVID-19 were less likely than those with mild disease to have alterations in smell (OR 0.44, 95\% CI $0.28-0.68$ ) in 8 studies and taste (OR 0.62 , 95\% CI $0.42-0.91)$ in 5 studies. No significant association was found between other neurologic manifestations with the severity of COVID-19. Table 3 represents the pooled association of various neurologic manifestations with severity of COVID-19, including the individual association of various neurologic diagnoses with severity of COVID-19 for which meta-analyses were not possible. No significant deviation was observed after controlling the false discovery rate (eTable 8 , links.lww.com/ WNL/B607).

\section{Publication Bias}

The risk of bias was assessed for neurologic manifestations for which $\geq 10$ studies were pooled. The asymmetry of funnel plot was apparent, and the Egger test was significant for dizziness $(p=0.003)$, disturbance of consciousness $(p=0.006)$, and stroke $(p=0.002)$. Twenty Egger tests were conducted, of which 3 were significant $(p<0.05)$ and underwent trim-and- 
Figure 2 Forest Plot Depicting the Pooled Prevalence of Stroke

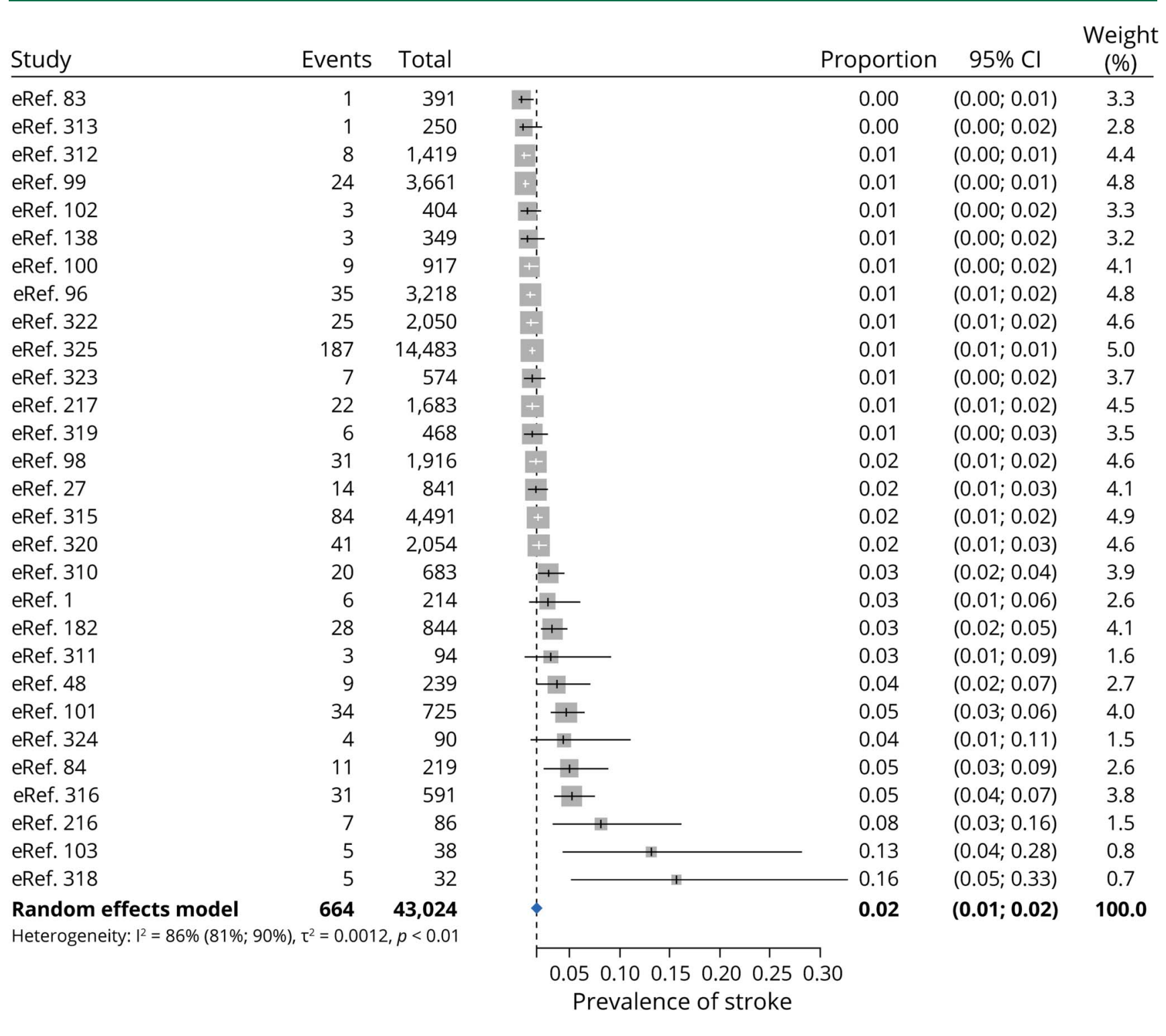

$\mathrm{Cl}=$ confidence interval.

fill analysis. For these 3 manifestations, we used the Duval and Tweedie trim-and-fill procedure and observed that studies with a lower prevalence were missing in dizziness, disturbance of consciousness, and total stroke. The shape of the funnel plots was symmetric for the rest of the neurologic manifestations assessed for the presence of publication bias.

While assessing the association between neurologic manifestations and severity of COVID-19, we did not find the presence of significant publication bias for any manifestations assessed using the shape of the funnel plots and the Egger regression test. The funnel plots and their respective $p$ values are depicted in eFigure 2 (links.lww.com/WNL/ B607).

\section{Meta-regression and Subgroup Analysis}

In an assessment of the prevalence of neurologic manifestations in COVID-19, risk of bias was significantly associated with pooled prevalence for acute confusion/delirium ( $p=$ $\left.0.001, R^{2}=3.49 \%\right)$ and myalgia or fatigue $\left(p=0.0001, R^{2}=\right.$ $41.09 \%$ ), where $R^{2}$ is the degree of heterogeneity accounted for. A subgroup analysis by risk of bias for acute confusion/ delirium demonstrated that 2 studies with moderate risk of bias had a pooled prevalence of $42 \%$ (95\% CI 7\%-83\%), while the pooled prevalence dropped to $11 \%$ (95\% CI 7\%-16\%) for 17 studies having a low risk of bias. A similar trend was observed while conducting the subgroup analysis for myalgia or fatigue. On stratification, a single study with a high risk of bias had a high prevalence of $68 \%$ (95\% CI 48\%-85\%), followed by 6 studies with moderate risk of bias $43 \%$ (95\% CI 
Table 2 Prevalence of Various Neurologic Diagnoses Included in the Systematic Review and Meta-analysis

\begin{tabular}{|c|c|c|c|c|c|c|}
\hline Study & Variables & Studies, $\mathbf{n}$ & Pooled events, $n$ & Pooled sample size, $n$ & Pooled prevalence $(95 \% \mathrm{Cl}), \%$ & $I^{2}$ value, $\%$ \\
\hline \multirow[t]{4}{*}{1} & Stroke & 29 & 664 & 43,024 & $2(1-2)$ & 86 \\
\hline & Ischemic stroke/TIA & 29 & 527 & 43,024 & $1(1-2)$ & 83 \\
\hline & Hemorrhagic stroke & 21 & 133 & 36,972 & $0.31(0.15-0.50)$ & 73 \\
\hline & Cerebral venous thrombosis & 2 & 4 & 14,573 & $0.12(0-2)$ & 78 \\
\hline 2 & Neuropsychiatric disorders & 3 & 243 & 1,293 & $24(2-61)$ & 99 \\
\hline 3 & Encephalopathy & 4 & 463 & 5,668 & $7(1-17)$ & 98 \\
\hline 4 & Skeletal muscle injury ${ }^{a}$ & 4 & 111 & 1,545 & $5(1-12)$ & 95 \\
\hline 5 & Myopathy ${ }^{\mathrm{b}}$ & 3 & 55 & 5,736 & $2(0-4)$ & 95 \\
\hline 6 & Movement disorder & 5 & 48 & 6,581 & $1(0-1)$ & 37 \\
\hline 7 & CIN/polyneuropathy & 5 & 48 & 7,251 & $1(0-2)$ & 90 \\
\hline 8 & Status epilepticus & 2 & 2 & 282 & $1(0-5)$ & 53 \\
\hline 9 & Encephalitis & 4 & 8 & 4,658 & $0.30(0-1)$ & 80 \\
\hline 10 & Guillain-Barre syndrome & 4 & 22 & 7,403 & $0.28(0-1)$ & 0 \\
\hline 11 & Parainfectious radiculitis & 2 & 2 & 858 & $0.23(0-1)$ & 0 \\
\hline 12 & PRES & 3 & 6 & 4,311 & $0.12(0.02-0.27)$ & 12 \\
\hline 13 & Dysexecutive syndrome & 1 & 14 & 39 & $36(21-53)$ & - \\
\hline 14 & Dysautonomia & 1 & 21 & 841 & $2(2-4)$ & - \\
\hline 15 & Restless leg syndrome & 1 & 4 & 239 & $2(0-4)$ & - \\
\hline 16 & Rhabdomyolysis & 1 & 2 & 509 & $0.39(0.05-1)$ & - \\
\hline 17 & Miller-Fisher syndrome & 1 & 1 & 2,054 & $0.05(0-0.27)$ & - \\
\hline
\end{tabular}

Abbreviations: $\mathrm{Cl}=$ confidence interval; $\mathrm{CIN}=$ critical illness neuropathy: PRES = posterior reversible encephalopathy syndrome.

${ }^{a}$ Includes significant creatinine kinase elevation.

${ }^{b}$ Includes critical illness myopathy.

$33 \%-53 \%)$, while the lowest pooled prevalence was observed for 15 studies having a low risk of bias $24 \%$ (95\% CI $19 \%-29 \%)$. This subgroup analysis is presented in eTables 9 and 10 (links.lww.com/WNL/B607). Another subgroup analysis by last month of data extraction showed that pooled prevalence of headache was higher from April to September $2020(16 \%-22 \%)$ compared to the initial 3 months $(8 \%-14 \%$ in January-March 2020) (eTable 11).

\section{Neurologic Symptoms in COVID-19 in the Elderly and Young Subpopulations}

Subgroup analyses were conducted on studies that included or disaggregated data on patients with COVID-19 who were $\geq 60$ years and those $<18$ years of age presenting with neurologic symptoms. For the elderly, we found 13 studies reporting solely on older patients and 2 studies with disaggregated data, representing 3,176 hospitalized patients presenting with 10 neurologic symptoms, with the most prevalent ( $95 \% \mathrm{CI}$, number of studies) as follows: acute confusion/delirium 34\% (95\% CI 23\%-46\%, 5 studies), fatigue $20 \%$ (95\% CI 11\%-31\%, 9 studies), myalgia $11 \%$
(95\% CI 7\%-15\%, 10 studies), dizziness 5\% (95\% CI 2\%-9\%, 3 studies), and headache 5\% (95\% CI 2\%-8\%, 10 studies). eTable 12 (links.lww.com/WNL/B607) presents the pooled prevalence of neurologic symptoms in the elderly COVID-19 subpopulation, including the individual prevalence of neurologic symptoms for which meta-analyses were not possible.

For patients with COVID-19 who were $<18$ years of age, we found 20 studies with 3,051 hospitalized patients presenting with 10 neurologic symptoms, with the most prevalent (95\% CI, number of studies) as follows: fatigue or myalgia $17 \%$ (95\% CI 9\%-26\%, 2 studies); smell or taste impairment 13\% (95\% CI 6\%-22\%, 2 studies); headache $10 \%$ (95\% CI 5\%-15\%, 13 studies); fatigue 9\% (95\% CI $3 \%-18 \%$, 9 studies); myalgia $7 \%$ (95\% CI $2 \%-15 \%, 5$ studies); seizure 4\% (95\% CI 2\%-6\%, 2 studies); and smell impairment 3\% (95\% CI 1\%-5\%, 5 studies). eTable 13 (links.lww.com/WNL/B607) presents the pooled prevalence of neurologic symptoms in the young COVID-19 subpopulation, including the individual prevalence of 
Table 3 Results From Systematic Review and Meta-analysis of Patients With COVID-19 (Severe and Nonsevere) Developing Neurologic Manifestations (Symptoms and Diagnosis)

\begin{tabular}{|c|c|c|c|c|c|c|}
\hline Study & Variables & Studies, $\mathrm{n}$ & $\begin{array}{l}\text { Severe COVID-19 } \\
\text { (event/total), } n\end{array}$ & $\begin{array}{l}\text { Nonsevere COVID-19 } \\
\text { (event/total), } n\end{array}$ & OR $(95 \% \mathrm{Cl})$ & $p$ Value \\
\hline 1 & Skeletal muscle injury & 2 & $69 / 417$ & $36 / 638$ & $3.29(2.15-5.04)$ & $<0.0001$ \\
\hline 2 & Smell impairment ${ }^{a}$ & 8 & $27 / 670$ & $130 / 1,355$ & $0.44(0.28-0.68)$ & 0.0003 \\
\hline 3 & Disturbance of consciousness & 4 & $95 / 450$ & $21 / 652$ & $5.68(2.08-15.50)$ & 0.0007 \\
\hline 4 & Fatigue & 33 & $916 / 1,968$ & $2067 / 5,358$ & $1.27(1.06-1.51)$ & 0.009 \\
\hline 5 & Taste impairment ${ }^{a}$ & 5 & $38 / 617$ & $138 / 1,221$ & $0.62(0.42-0.91)$ & 0.01 \\
\hline 6 & Acute confusion/delirium & 4 & $103 / 1,031$ & $84 / 1,418$ & $3.21(0.82-12.59)$ & 0.09 \\
\hline 7 & Stroke & 3 & $14 / 426$ & $9 / 644$ & $2.03(0.83-4.96)$ & 0.12 \\
\hline 8 & Seizure & 3 & $6 / 426$ & $3 / 644$ & $2.40(0.63-9.19)$ & 0.20 \\
\hline 9 & Headache and dizziness ${ }^{b}$ & 3 & $24 / 131$ & $64 / 454$ & $1.29(0.76-2.18)$ & 0.34 \\
\hline 10 & Myalgia & 31 & $477 / 2,146$ & $1,229 / 5,859$ & $1.08(0.90-1.30)$ & 0.40 \\
\hline 11 & Movement disorder & 2 & $2 / 463$ & $2 / 887$ & $2.02(0.29-13.82)$ & 0.47 \\
\hline 12 & Myalgia or fatigue ${ }^{b}$ & 4 & $52 / 102$ & $82 / 262$ & $1.51(0.32-7.11)$ & 0.60 \\
\hline 13 & Vision impairment & 2 & $2 / 417$ & $2 / 638$ & $1.55(0.23-10.70)$ & 0.65 \\
\hline 14 & Headache & 32 & $293 / 2,262$ & 799/5,998 & $1.05(0.84-1.32)$ & 0.67 \\
\hline 15 & Dizziness & 11 & $90 / 1,084$ & $185 / 2,024$ & $0.98(0.65-1.47)$ & 0.92 \\
\hline 16 & Neuropsychiatric disorder & 2 & $75 / 338$ & $95 / 518$ & $1.00(0.30-3.31)$ & 0.99 \\
\hline 17 & Myopathy & 1 & $22 / 329$ & $4 / 512$ & $9.10(3.11-26.66)$ & $<0.0001$ \\
\hline 18 & Neuralgia & 1 & $4 / 88$ & $1 / 126$ & $5.95(0.65-54.19)$ & 0.11 \\
\hline 19 & Dysautonomia & 1 & $6 / 329$ & $15 / 512$ & $0.62(0.24-1.60)$ & 0.32 \\
\hline 20 & Encephalopathy & 1 & $1 / 134$ & $8 / 375$ & $0.34(0.04-2.78)$ & 0.32 \\
\hline 21 & Rhabdomyolysis & 1 & $1 / 134$ & $1 / 375$ & $2.81(0.17-45.28)$ & 0.46 \\
\hline 22 & Encephalitis & 1 & $2 / 9$ & $1 / 6$ & $1.42(0.10-20.44)$ & 0.79 \\
\hline
\end{tabular}

Abbreviations: $\mathrm{Cl}$ = confidence interval; COVID-19 = coronavirus disease 2019.

${ }^{a}$ When patients with severe COVID-19 reached hospital, they probably were not in a position to give a history for smell and taste impairment. However, for completeness of data, we noted that the recorded number of patients with smell and taste impairment was higher in the nonsevere group than in the severe group.

${ }^{b}$ These studies did not separate myalgia from fatigue and headache from dizziness.

neurologic symptoms for which meta-analyses were not possible.

\section{Neurologic Symptoms in COVID-19 Cases Analyzed by Hospitalization Status}

We included 129,786 hospitalized and 9,188 nonhospitalized cases of COVID-19. The data for neurologic symptoms in nonhospitalized cases of COVID-19 could be extracted from only 13 studies. Smell impairment (50\%), taste impairment (44\%), headache $(31 \%)$, and myalgia (31\%) were found to be more common in nonhospitalized cases, whereas fatigue (31\%) and myalgia or fatigue (30\%) were found to be more common in hospitalized cases. A full comparison is available in eTable 14 (links.lww.com/ WNL/B607).

\section{Mortality in Patients With COVID-19 With and Without Neurologic Manifestations}

Mortality in patients with COVID-19 having $\geq 1$ neurologic manifestations was assessed in 21 studies included in the systematic review and meta-analysis. A total of 770 patients died of 2,982 experiencing neurologic manifestations. The pooled prevalence of mortality in patients with COVID-19 with $\geq 1$ neurologic manifestations was $27 \%$ (95\% CI 19\%-35\%).

The association between mortality and neurologic manifestations was assessed in 13 studies consisting of 2,706 and 10,808 patients with COVID-19 with and without neurologic manifestations, respectively. There was a nonsignificant trend toward higher odds of mortality in patients with neurologic manifestations compared to those without them (OR 1.39, 
95\% CI 0.92-2.11). For patients $\geq 60$ years of age, the presence of neurologic manifestations was significantly associated with increased mortality (OR 1.80, 95\% CI 1.11-2.91) (Figure 3).

\section{Discussion}

It is increasingly apparent that SARS-CoV-2 can have many effects on the CNS and peripheral nervous system. In this review, we report all acute neurologic manifestations reported in COVID-19, comorbid conditions associated with COVID-19 infection, the association with acute neurologic manifestations and severity or mortality, and subgroup analyses of neurologic manifestations by age group. Our pooled prevalence estimates indicate that up to one-third of patients with COVID-19 analyzed in our review experienced at least 1 neurologic manifestation and that 1 in 50 people developed a stroke.

Our review shows that preexisting neurologic conditions are a common comorbidity associated with COVID-19. After hypertension and diabetes, the combined comorbidity of cardiovascular/cerebrovascular disease was the third most commonly reported comorbidity associated with COVID-19. Disaggregated data released from national and international COVID-19 registries similarly indicate a high prevalence of preexisting neurologic conditions and an association with severe disease. $^{25-27}$

This review identified 41 neurologic manifestations (24 symptoms and 17 diagnoses). The following neurologic symptoms were found to be common in a large number of studies: fatigue, myalgia, smell and taste impairment, headaches, and agitation. Neuropsychiatric disorders were found to affect 1 in 4 hospitalized patients, although data were available from only 3 studies. Critically, the pooled prevalence in our review for the diagnosis of stroke was $2 \%$, with data extracted from 29 studies; the majority of studies reported a prevalence between $1 \%$ and $3 \%$. The pooled prevalence for stroke reported in our review in patients with COVID-19 indicates an alarming, enduring neurologic morbidity associated with the pandemic. In addition, we note that this pooled prevalence is far higher than has previously been reported for patients with influenza. One recent study ${ }^{28}$ compared the risk of stroke in COVID-19 and influenza and found the prevalence of stroke to be $0.2 \%$ in influenza vs $1.2 \%$ in COVID-19.

Acute confusion/delirium is significantly more common in older people who have COVID-19, with data from 5 studies demonstrating that 1 in 3 hospitalized older patients with COVID-19 are affected (pooled prevalence 34\%) compared with $5 \%$ in young adults and $12 \%$ for all ages. This bears implications for both cognitive outcomes and mortality. Delirium in older hospitalized patients has previously been demonstrated to be an independent risk factor for mortality 1 year after hospitalization, increasing the risk of death by $>2$-fold. ${ }^{29}$ Moreover, delirium in older adults is a risk factor for developing dementia, increasing the risk nearly 9-fold over 10 years of follow-up for adults $\geq 85$ years of age. ${ }^{30}$

For adults with COVID-19 who are $>60$ years of age, the presence of any neurologic manifestation was associated with increased mortality (OR 1.80, 95\% CI 1.11-2.91). We also note that the relationship between COVID-19 severity and neurologic manifestations may be bidirectional; critically ill patients are more likely to experience multiorgan system dysfunction.

Therefore, our analysis shows age and severity as predictors of neurologic findings. However, analysis of other potential and independent predictors was neither feasible from the published data nor within the scope of this review.

Figure 3 Forest Plot Depicting the Association Between Presence of Neurologic Manifestations and Mortality of Patients With COVID-19 $\geq 60$ Years of Age

\begin{tabular}{|c|c|c|c|c|c|c|c|c|}
\hline Study & Events & $\begin{array}{l}\text { Cases } \\
\text { total }\end{array}$ & Events & $\begin{array}{c}\text { Controls } \\
\text { total }\end{array}$ & Odds ratio & OR & $95 \% \mathrm{Cl}$ & $\begin{array}{c}\text { Weight } \\
(\%)\end{array}$ \\
\hline eRef. 311 & 14 & 47 & 17 & 47 & 1 & 0.75 & $(0.32 ; 1.77)$ & 10.3 \\
\hline eRef. 196 & 238 & 720 & 546 & 1,495 & +1 & 0.86 & $(0.71 ; 1.04)$ & 15.1 \\
\hline eRef. 188 & 53 & 352 & 51 & 329 & +1 & 0.97 & $(0.64 ; 1.47)$ & 13.8 \\
\hline eRef. 104 & 19 & 118 & 2 & 22 & 4 & 1.92 & $(0.41 ; 8.90)$ & 6.0 \\
\hline eRef. 315 & 211 & 606 & 751 & 3,885 & + & 2.23 & $(1.85 ; 2.68)$ & 15.1 \\
\hline eRef. 98 & 10 & 31 & 264 & 1,885 & $\begin{array}{ll}11 \\
11\end{array}$ & 2.92 & $(1.36 ; 6.28)$ & 11.1 \\
\hline eRef. 310 & 10 & 20 & 167 & 663 & 1 & 2.97 & $(1.21 ; 7.26)$ & 10.1 \\
\hline eRef. 218 & 47 & 105 & 80 & 471 & + & 3.96 & $(2.52 ; 6.23)$ & 13.6 \\
\hline eRef. 319 & 2 & 6 & 11 & 99 & $\begin{array}{ll}1 \\
1\end{array}$ & 4.00 & $(0.66 ; 24.43)$ & 4.9 \\
\hline Random effects model & 604 & 2,005 & 1,889 & 8,896 & + & 1.80 & $(1.11 ; 2.91)$ & 100.0 \\
\hline \multicolumn{9}{|c|}{ Heterogeneity: $I^{2}=90 \%(84 \% ; 94 \%), \tau^{2}=0.3914, p<0.01$} \\
\hline
\end{tabular}

CI = confidence interval; COVID-19 = coronavirus disease 2019; OR = odds ratio. 
It has been posited that there may be pathophysiologic basis for the association between smell and taste impairment and mild COVID-19; inflammation in mucosal membranes may play a role in preventing migration of the virus elsewhere in the body. ${ }^{31}$ Moreover, patients with severe COVID-19 may not have been able to provide a clear history regarding smell or taste impairment, and we note that the majority of the data we have analyzed come from hospitalized patients. ${ }^{32}$

Multiple, potentially interacting, mechanisms have been proposed for the neurologic manifestations, including hypoxia, severe cytokine storm during infection and postinfectious autoimmune responses, hypercoagulability, endotheliopathy, multiple organ failure (e.g., liver failure leading to metabolic derangement), and possibly direct neuro-invasion. The neuro-invasive and neurotropic potential of SARS-CoV-2 is controversial but may be explained by the expression of angiotensin-converting enzyme-2 receptor in the brain. ${ }^{33}$

There are several important limitations to this review. First, there are few data from prospective studies; most data came from retrospective cohorts or case series. Second, standardized classifications, definitions, and diagnostic criteria for neurologic manifestations were not uniformly used or reported. Moreover, studies relating to many manifestations were not suitable for pooling. Third, because the vast majority (89\%) of data analyzed came from hospitalized cases, our pooled prevalence estimates of neurologic manifestations, especially those of severe manifestations such as stroke, may not represent community prevalence. Therefore, we cannot draw conclusions about the prevalence of neurologic manifestations among patients with COVID-19 in the community. In addition, interpretation of data on preexisting neurologic conditions and COVID-19 diagnoses is limited due to the proportion of hospitalized cases studied. Fourth, 14 studies in our review used positive serology as one of the diagnostic criteria. However, they included hospitalized patients, and none of these studies relied on positive serology alone and used either PCR testing or clinical suspicion as a criterion. It is possible, however, that some of the patients included in these studies may have been experiencing neurologic symptoms from parainfectious/postinfectious syndromes or secondary autoimmune diseases due to COVID-19.

Meta-analyses for most outcomes in this review had high heterogeneity, which could be explained only partly by metaregression and subgroup analyses. It is expected that the patient populations in the included studies were clinically diverse, having presented to centers with varied referral pathways, and this may have contributed to the heterogeneity observed. For almost all symptoms, studies with a higher risk of bias yielded higher pooled prevalence, indicating overestimation from bias in selection or measurement. Bias is known to exaggerate effect estimates in studies. ${ }^{34}$ Studies were varying in terms of biases in selection, measurement, and reporting. Confounding bias limited severity and mortality analyses in this review in that given estimates were not adjusted for potential confounders such as comorbid conditions.
The timing of symptom onset is not reported in most studies, which has implications for understanding causality, and we are unable to distinguish acute neurologic manifestations caused by COVID-19 from the incidence of similar symptoms and diagnoses in the general population. In addition, this review has focused mainly on new-onset neurologic symptoms. We have not analyzed worsening of underlying or preexisting neurologic disorders, for which data are emerging in relation to COVID-19 and dementia, Parkinson disease, epilepsy, ${ }^{35}$ myasthenia gravis, ${ }^{36}$ and multiple sclerosis. ${ }^{37}$ We also did not analyze the temporal trends in the prevalence of neurologic symptoms because doing so was beyond the scope of this review.

In addition, we have included fatigue, a nonspecific neurologic symptom, which can be comorbid with conditions involving multiple organ systems. Central fatigue (specifically mental/ cognitive fatigue, as opposed to purely physical weakness) in many conditions, including serious viral infections, is thought to be due at least partially to neuroinflammatory processes or cascades precipitated by peripheral cytokines. ${ }^{38}$ We recognize that purely physical weakness is not necessarily CNS mediated. Unfortunately, none of the studies we analyzed included the granularity of data to distinguish between mental/ cognitive and physical fatigue.

It is important to note that the majority of the data analyzed in this review are from high- and middle-income countries. There are few data from low-income countries on neurologic manifestations available in published studies to date.

We hope that the data provided in this review might aid clinical practice and future research. Pooled prevalence estimates reported here may be used to design or validate clinical checklists for detecting neurologic manifestations that may otherwise be missed. In addition, neurologic manifestations may be factored into risk stratification, especially for older persons with COVID-19, given the association with higher mortality for any neurologic manifestation in this subpopulation.

Several questions remain as to the characteristics, timing, and severity of neurologic manifestations of COVID-19. Welldesigned cohort, case-control, and population-based studies are required to understand risk factors and to suggest underlying mechanisms, which should be confirmed by neuropathologic studies. The timing of risk for acute, subacute, and long-term neurologic manifestations remains unclear, and this is particularly relevant for stroke and cognitive impairment. It is vital to have data on neurologic manifestations from geographically and resource diverse settings. Furthermore, as future studies are conducted, neurologic manifestations of COVID-19 can be considered for each variant of concern whenever it would be feasible to conduct the necessary testing. It is indeed possible that certain variants may be more virulent and have worse or previously unseen impacts on the nervous system. One year into the pandemic, it is critical to have robust, harmonized standards for methodology and 
reporting to minimize the risk of bias and to enhance confidence in our understanding of the true neurologic implications of this illness.

\section{Disclaimer}

The authors alone are responsible for the views expressed in this article and they do not necessarily represent the views, decisions, or policies of the institutions with which they are affiliated.

\section{Study Funding}

K. Prasad received funding from the WHO to support this systematic review and meta-analysis. S. Misra is a DSTINSPIRE Fellow supported by Department of Science and Technology, Government of India. S.H.-Y. Chou receives research funding from the NIH National Center for Advancing Translational Sciences through grant UL1 TR001857 (University of Pittsburgh/Chou), the National Institute of Neurological Disorders and Stroke (R21-NS113037), and the University of Pittsburgh School of Medicine Dean's Faculty Advancement Award. E.L. Fink has a research grant from Neurocritical Care Society INCLINE grant, NIH (National Institute of Neurological Disorders and Stroke) R01 NS096714. C.A. Pardo is supported by NIH R01 NS110122 and Bart McLean Fund for Neuroimmunology Research. B.D. Michael is supported to conduct clinical COVID-19 neuroscience research by the UK Research and Innovation (UKRI)/Medical Research Council (MRC) (MR/V03605X/ 1); for additional neurological inflammation research due to SARS-CoV2 and associated viral infection, B.D.M. is also supported by grants from the MRC/UKRI (MR/V007181// 1), MRC (MR/T028750/1), and Wellcome (ISSF201902/ 3). T. Solomon is supported by the National Institute for Health Research (NIHR) Health Protection Research Unit in Emerging and Zoonotic Infections (grants IS-HPU-111210117 and NIHR200907), NIHR Programme Grant for Applied Research (No. RP-PG-0108-10,048), NIHR Global Health Research Group on Brain Infections (No. 17/63/ 110), and the European Union's Horizon 2020 research and innovation program ZikaPLAN (Preparedness Latin America Network), grant agreement 734584.

\section{Disclosure}

S.H.-Y. Chou serves as a member of Board of Directors for the Neurocritical Care Society. K.T. Thakur is being funded by Centers for Disease Control and Prevention on COVID-19 related research. T. Solomon was chair/co-chair of the UKRI/ NIHR COVID-19 Rapid Response and Rolling Funding Initiatives and is an advisor to the UK COVID-19 Therapeutics Advisory Panel and a member of the MHRA COVID19 Vaccines Benefit Risk Expert Working Group. E. Beghi reports grants from Italian Ministry of Health, grants from SOBI, personal fees from Arvelle Therapeutics, and grants from American ALS Association, outside the submitted work. S. Misra, K. Kolappa, M. Prasad, D. Radhakrishnan, B.D.

Michael, A.S. Winkler, A. Guekht, C.A. Pardo, G.K. Wood, E.L. Fink, E. Schmutzhard, A. Kheradmand, F.K. Hoo, A. Kumar, A. Das, A.K. Srivastava, A. Agarwal, T. Dua, and K. Prasad report no disclosures relevant to the manuscript. Go to Neurology.org/N for full disclosures.

\section{Publication History}

This manuscript was previously published on medRxiv; doi. org/10.1101/2021.04.20.21255780. Received by Neurology May 5, 2021. Accepted in final form September 30, 2021.

Appendix Authors

\begin{tabular}{lll}
\hline Name & Location & Contribution \\
\hline $\begin{array}{ll}\text { Shubham Misra, } \\
\text { MTech }\end{array}$ & $\begin{array}{l}\text { Department of Neurology, } \\
\text { All India Institute of }\end{array}$ & Drafting/revision of the \\
Medical Sciences, New & manuscript for content, \\
& including medical writing \\
& for content; major role in \\
& the acquisition of data; \\
& study concept or design; \\
& analysis or interpretation \\
& of data
\end{tabular}

\begin{tabular}{lll}
\hline Kavitha & Brain Health Unit, World & Drafting/revision of the \\
Kolappa, MD & Health Organization & $\begin{array}{l}\text { manuscript for content, } \\
\text { including medical writing } \\
\text { for content; study concept } \\
\text { or design; analysis or } \\
\text { interpretation of data }\end{array}$ \\
& \\
\hline
\end{tabular}

\begin{tabular}{|c|c|c|}
\hline $\begin{array}{l}\text { Manya Prasad, } \\
\text { MD }\end{array}$ & $\begin{array}{l}\text { Department of Clinical } \\
\text { research and } \\
\text { Epidemiology, Institute of } \\
\text { Liver and Biliary Sciences, } \\
\text { New Delhi, India }\end{array}$ & $\begin{array}{l}\text { Drafting/revision of the } \\
\text { manuscript for content, } \\
\text { including medical writing } \\
\text { for content; study concept } \\
\text { or design; analysis or } \\
\text { interpretation of data }\end{array}$ \\
\hline
\end{tabular}

Divya Department of Neurology, Drafting/revision of the

$\begin{array}{ll}\text { Radhakrishnan, } & \text { All India Institute of } \\ \text { DM } & \text { Medical Sciences, New } \\ & \text { Delhi }\end{array}$
manuscript for content, including medical writing for content; major role in the acquisition of data; study concept or design

\begin{tabular}{|c|c|c|}
\hline $\begin{array}{l}\text { Kiran T Thakur, } \\
\text { MD }\end{array}$ & $\begin{array}{l}\text { Columbia University Irving } \\
\text { Medical Center-New York } \\
\text { Presbyterian Hospital, NY }\end{array}$ & $\begin{array}{l}\text { Drafting/revision of the } \\
\text { manuscript for content, } \\
\text { including medical writing } \\
\text { for content; major role in } \\
\text { the acquisition of data }\end{array}$ \\
\hline $\begin{array}{l}\text { Tom Solomon, } \\
\text { FRCP }\end{array}$ & $\begin{array}{l}\text { Institute of Infection, } \\
\text { Veterinary and Ecological } \\
\text { Sciences, University of } \\
\text { Liverpool, UK }\end{array}$ & $\begin{array}{l}\text { Drafting/revision of the } \\
\text { manuscript for content, } \\
\text { including medical writing } \\
\text { for content; analysis or } \\
\text { interpretation of data }\end{array}$ \\
\hline $\begin{array}{l}\text { Benedict Daniel } \\
\text { Michael, PhD }\end{array}$ & $\begin{array}{l}\text { Institute of Infection, } \\
\text { Veterinary and Ecological } \\
\text { Sciences, University of } \\
\text { Liverpool, UK; Department } \\
\text { of Neurology, Walton } \\
\text { Centre NHS Foundation } \\
\text { Trust, Liverpool, UK }\end{array}$ & $\begin{array}{l}\text { Drafting/revision of the } \\
\text { manuscript for content, } \\
\text { including medical writing } \\
\text { for content; analysis or } \\
\text { interpretation of data }\end{array}$ \\
\hline $\begin{array}{l}\text { Andrea Sylvia } \\
\text { Winkler, PhD }\end{array}$ & $\begin{array}{l}\text { Center for Global Health, } \\
\text { Department of Neurology, } \\
\text { Technical University of } \\
\text { Munich, Germany; } \\
\text { Centre for Global Health, } \\
\text { Institute of Health and } \\
\text { Society, University of } \\
\text { Oslo, Norway }\end{array}$ & $\begin{array}{l}\text { Drafting/revision of the } \\
\text { manuscript for content, } \\
\text { including medical writing } \\
\text { for content }\end{array}$ \\
\hline
\end{tabular}


Appendix (continued)

\begin{tabular}{lll}
\hline Name & Location & Contribution \\
\hline $\begin{array}{ll}\text { Ettore Beghi, } \\
\text { MD }\end{array}$ & $\begin{array}{l}\text { Istituto di Ricerche } \\
\text { Farmacologiche Mario } \\
\text { Negri IRCCS, Milan, Italy }\end{array}$ & $\begin{array}{l}\text { Drafting/revision of the } \\
\text { manuscript for content, } \\
\text { including medical writing } \\
\text { for content }\end{array}$
\end{tabular}

\begin{tabular}{|c|c|c|}
\hline Alla Guekht, MD & $\begin{array}{l}\text { Moscow Research and } \\
\text { Clinical Center for } \\
\text { Neuropsychiatry and } \\
\text { Pirogov Russian National } \\
\text { Research Medical } \\
\text { University; Moscow Russia }\end{array}$ & $\begin{array}{l}\text { Drafting/revision of the } \\
\text { manuscript for content, } \\
\text { including medical writing } \\
\text { for content }\end{array}$ \\
\hline $\begin{array}{l}\text { Carlos A Pardo, } \\
\text { MD }\end{array}$ & $\begin{array}{l}\text { Departments of Neurology } \\
\text { and Pathology, Johns } \\
\text { Hopkins University } \\
\text { School of Medicine, } \\
\text { Baltimore, MD }\end{array}$ & $\begin{array}{l}\text { Drafting/revision of the } \\
\text { manuscript for content, } \\
\text { including medical writing } \\
\text { for content }\end{array}$ \\
\hline $\begin{array}{l}\text { Greta Karen } \\
\text { Wood, MRes }\end{array}$ & $\begin{array}{l}\text { Institute of Infection, } \\
\text { Veterinary and Ecological } \\
\text { Sciences, University of } \\
\text { Liverpool, UK; Department } \\
\text { of Neurology, Walton } \\
\text { Centre NHS Foundation } \\
\text { Trust, Liverpool, UK; NIHR } \\
\text { Health Protection } \\
\text { Research Unit for } \\
\text { Emerging and Zoonotic } \\
\text { Infection, Liverpool, UK }\end{array}$ & $\begin{array}{l}\text { Drafting/revision of the } \\
\text { manuscript for content, } \\
\text { including medical writing } \\
\text { for content }\end{array}$ \\
\hline
\end{tabular}

Sherry Hsiang-Yi University of Pittsburgh Chou, MD School of Medicine, PA

Drafting/revision of the manuscript for content including medical writing for content

\begin{tabular}{lll}
$\begin{array}{l}\text { Ericka L Fink, } \\
\text { MD }\end{array}$ & $\begin{array}{l}\text { Department of Critical } \\
\text { Care Medicine, UPMC } \\
\text { Children's Hospital of } \\
\text { Pittsburgh, PA }\end{array}$ & $\begin{array}{l}\text { Drafting/revision of the } \\
\text { manuscript for content, } \\
\text { including medical writing } \\
\text { for content }\end{array}$ \\
\hline $\begin{array}{l}\text { Erich } \\
\text { Schmutzhard, } \\
\text { MD }\end{array}$ & $\begin{array}{l}\text { Department of Neurology, } \\
\text { Medical University } \\
\text { Innsbruck, Austria }\end{array}$ & $\begin{array}{l}\text { Drafting/revision of the } \\
\text { manuscript for content, } \\
\text { including medical writing } \\
\text { for content }\end{array}$ \\
\hline $\begin{array}{l}\text { Amir } \\
\text { Kheradmand, } \\
\text { MD }\end{array}$ & $\begin{array}{l}\text { Departments of Neurology } \\
\text { and Otolaryngology-Head } \\
\text { \& Neck Surgery, The Johns }\end{array}$ & $\begin{array}{l}\text { Drafting/revision of the } \\
\text { manuscript for content, } \\
\text { including medical writing } \\
\text { for content }\end{array}$ \\
& $\begin{array}{l}\text { Hopkins Hospital, } \\
\text { Baltimore, MD }\end{array}$ & \\
\hline
\end{tabular}

\begin{tabular}{|c|c|c|}
\hline Fan Kee Hoo, MD & $\begin{array}{l}\text { Department of Neurology, } \\
\text { Faculty of Medicine and } \\
\text { Health Sciences, University } \\
\text { Putra Malaysia, Seri } \\
\text { Kembangan }\end{array}$ & $\begin{array}{l}\text { Drafting/revision of the } \\
\text { manuscript for content, } \\
\text { including medical writing } \\
\text { for content }\end{array}$ \\
\hline
\end{tabular}

Amit Kumar, Department of Neurology, Analysis or interpretation
$\begin{array}{ll}\text { Department of Neurology, } & \text { Analysis } \\ \text { All India Institute of } & \text { of data }\end{array}$ Medical Sciences, New Delhi

\begin{tabular}{lll}
\hline $\begin{array}{l}\text { Animesh Das, } \\
\text { DM }\end{array}$ & $\begin{array}{l}\text { Department of Neurology, } \\
\text { All India Institute of } \\
\text { Medical Sciences, New } \\
\text { Delhi }\end{array}$ & $\begin{array}{l}\text { Analysis or interpretation } \\
\text { of data }\end{array}$ \\
\hline $\begin{array}{l}\text { Achal K } \\
\text { Srivastava, DM }\end{array}$ & $\begin{array}{l}\text { Department of Neurology, } \\
\text { All India Institute of } \\
\text { Medical Sciences, New } \\
\text { Delhi }\end{array}$ & $\begin{array}{l}\text { Analysis or interpretation } \\
\text { of data }\end{array}$ \\
\hline $\begin{array}{l}\text { Ayush Agarwal, } \\
\text { DM }\end{array}$ & $\begin{array}{l}\text { Department of Neurology, } \\
\text { All India Institute of } \\
\text { Medical Sciences, New } \\
\text { Delhi }\end{array}$ & \\
\hline
\end{tabular}

\section{Appendix (continued)}

\begin{tabular}{lll}
\hline Name & Location & Contribution \\
\hline Tarun Dua, MD & $\begin{array}{l}\text { Brain Health Unit, World } \\
\text { Health Organization }\end{array}$ & $\begin{array}{l}\text { Drafting/revision of the } \\
\text { manuscript for content, } \\
\text { including medical writing } \\
\text { for content; study concept } \\
\text { or design }\end{array}$ \\
\hline $\begin{array}{l}\text { Kameshwar } \\
\text { Prasad, DM }\end{array}$ & $\begin{array}{ll}\text { Rajendra Institute of } \\
\text { Medical Sciences, Ranchi, } \\
\text { Jharkhand, India }\end{array}$ & $\begin{array}{l}\text { Drafting/revision of the } \\
\text { manuscript for content, } \\
\text { including medical writing } \\
\text { for content; study concept } \\
\text { or design; analysis or } \\
\text { interpretation of data }\end{array}$ \\
& &
\end{tabular}

\section{References}

1. WHO coronavirus disease (COVID-19) dashboard [online]. Accessed February 17, 2021. covid19.who.int.

2. Gorbalenya AE, Baker SC, Baric RS, et al. The species severe acute respiratory syndrome-related coronavirus : classifying $2019-\mathrm{nCoV}$ and naming it SARS-CoV-2. Nature Microbiology, vol 5. Nature Publishing Group; 2020:536-544. Accessed February 8, 2021. nature.com/articles/s41564-020-0695-z.

3. Report of the WHO-China Joint Mission on Coronavirus Disease 2019 (COVID-19) [online]. Accessed February 8, 2021. who.int/publications-detail-redirect/report-ofthe-who-china-joint-mission-on-coronavirus-disease-2019-(covid-19).

4. Wong $\mathrm{CKH}$, Wong JYH, Tang EHM, Au CH, Wai AKC. Clinical presentations, laboratory and radiological findings, and treatments for 11,028 COVID-19 patients: a systematic review and meta-analysis. Sci Rep. 2020;10(1):19765.

5. Ellul MA, Benjamin L, Singh B, et al. Neurological associations of COVID-19. Lancet Neurol. 2020;19(9):767-783.

6. Helms J, Kremer S, Merdji H, et al. Neurologic features in severe SARS-CoV-2 infection. N Engl J Med. 2020;382(23):2268-2270.

7. Mao L, Jin H, Wang M, et al. Neurologic manifestations of hospitalized patients with coronavirus disease 2019 in Wuhan, China. JAMA Neurol.2020;77(6):683-690.

8. World Health Organization. Clinical management of COVID-19: interim guidance, 27 May 2020 [online]. World Health Organization. Accessed March 16, 2021. who.int/ iris/handle/10665/332196

9. COVID-19 clinical management: living guidance [online]. Accessed March 16, 2021. who.int/publications/i/item/WHO-2019-nCoV-clinical-2021-1.

10. Pinzon RT, Wijaya VO, Buana RB, Al Jody A, Nunsio PN. Neurologic characteristics in coronavirus disease 2019 (COVID-19): a systematic review and meta-analysis. Front Neurol. 2020;11:565.

11. Abdullahi A, Candan SA, Abba MA, et al. Neurological and musculoskeletal features of COVID-19: a systematic review and meta-analysis. Front Neurol. 2020;11:687.

12. Favas TT, Dev P, Chaurasia RN, et al. Neurological manifestations of COVID-19: a systematic review and meta-analysis of proportions. Neurol Sci. 2020;41(12): 3437-3470.

13. Beach SR, Praschan NC, Hogan C, et al. Delirium in COVID-19: a case series and exploration of potential mechanisms for central nervous system involvement. Gen Hosp Psychiatry. 2020;65:47-53.

14. Fridman S, Bres Bullrich M, Jimenez-Ruiz A, et al. Stroke risk, phenotypes, and death in COVID-19: systematic review and newly reported cases. Neurology. 2020;95(24): e3373-e3385.

15. Oxley TJ, Mocco J, Majidi S, et al. Large-vessel stroke as a presenting feature of Covid19 in the young. $N$ Engl J Med. 2020;382(20):e60.

16. Liotta EM, Batra A, Clark JR, et al. Frequent neurologic manifestations and encephalopathy-associated morbidity in COVID-19 patients. Ann Clin Transl Neurol. 2020;7(11):2221-2230.

17. WHO COVID-19 case definition [online]. Accessed April 8, 2021. who.int/publications-detail-redirect/WHO-2019-nCoV-Surveillance_Case_Definition-2020.2.

18. Moher D, Shamseer L, Clarke M, et al. Preferred Reporting Items for Systematic Review and Meta-Analysis Protocols (PRISMA-P) 2015 statement. Syst Rev. 2015;4(1):1.

19. PROSPERO protocol [online]. Accessed April 8, 2021. crd.york.ac.uk/prospero/ display_record.php?RecordID $=181867$.

20. Munn Z, Barker TH, Moola S, et al. Methodological quality of case series studies: an introduction to the JBI critical appraisal tool. JBI Database Syst Rev Implement Rep. 2020;18(10):2127-2133.

21. Freeman MF, Tukey JW. Transformations related to the angular and the square root. Ann Math Stat Inst Math Stat. 1950;21:607-611. Accessed March 16, 2021. projecteuclid.org/journals/annals-of-mathematical-statistics/volume-21/issue-4/ Transformations-Related-to-the-Angular-and-the-Square-Root/10.1214/aoms / 1177729756.full.

22. Egger M, Davey Smith G, Schneider M, Minder C. Bias in meta-analysis detected by a simple, graphical test. BMJ. 1997;315(7109):629-634.

23. Duval S, Tweedie R. Trim and fill: a simple funnel-plot-based method of testing and adjusting for publication bias in meta-analysis. Biometrics. 2000;56(2):455-463. 
24. Download R-3.6.2 for Windows: the R-Project for Statistical Computing [online]. Accessed April 8, 2021. cran.r-project.org/bin/windows/base/old/3.6.2/.

25. Herald TK. Dementia patients at most risk of falling prey to COVID-19: data [online]. 2020. Accessed February 17, 2021. koreaherald.com/view.php? $\mathrm{ud}=20200324000833$.

26. Garg S, Kim L, Whitaker M, et al. Hospitalization rates and characteristics of patients hospitalized with laboratory-confirmed coronavirus disease 2019 - COVID-NET, 14 states, March 1-30, 2020. MMWR Morb Mortal Wkly Rep. 2020;69(15):458-464.

27. About Lean European Open Survey on SARS-CoV-2 infected patients: monitoring SARSCoV-2 infected patients [online]. 2020. Accessed February 17, 2021. leoss.net/about/.

28. Merkler AE, Parikh NS, Mir S, et al. Risk of ischemic stroke in patients with coronavirus disease 2019 (COVID-19) vs patients with influenza. JAMA Neurol. 2020; 77(11):1-7.

29. McCusker J, Cole M, Abrahamowicz M, Primeau F, Belzile E. Delirium predicts 12month mortality. Arch Intern Med. 2002;162(4):457-463.

30. Davis DHJ, Muniz Terrera G, Keage H, et al. Delirium is a strong risk factor for dementia in the oldest-old: a population-based cohort study. Brain. 2012;135(pt 9): 2809-2816.

31. Lechien JR, Chiesa-Estomba CM, Beckers E, et al. Prevalence and 6-month recovery of olfactory dysfunction: a multicentre study of 1363 COVID-19 patients. J Intern Med. 2021;290(2):451-461.
32. Yan CH, Faraji F, Prajapati DP, Ostrander BT, DeConde AS. Self-reported olfactory loss associates with outpatient clinical course in COVID-19. Int Forum Allergy Rhinol. 2020;10(7):821-831.

33. Baig AM, Khaleeq A, Ali U, Syeda H. Evidence of the COVID-19 virus targeting the CNS: tissue distribution, host-virus interaction, and proposed neurotropic mechanisms. ACS Chem Neurosci. 2020;11(7):995-998.

34. Faggion CM, Wu Y-C, Scheidgen M, Tu Y-K. Effect of risk of bias on the effect size of meta-analytic estimates in randomized controlled trials in periodontology and implant dentistry. PLoS One. 2015;10(9):e0139030.

35. Kubota T, Kuroda N. Exacerbation of neurological symptoms and COVID-19 severity in patients with preexisting neurological disorders and COVID-19: a systematic review. Clin Neurol Neurosurg. 2021;200:106349.

36. Adhikari R, Suram VK, Deepika K, Joseph T. A fatal case of myasthenia gravis exacerbation in COVID-19 leading to acute respiratory failure. J Neurol Transl Neurosci. 2020;6(1):1087.

37. Kataria S, Tandon M, Melnic V, Sriwastava S. A case series and literature review of multiple sclerosis and COVID-19: clinical characteristics, outcomes and a brief review of immunotherapies. eNeurologicalSci 2020;21:100287.

38. Dantzer R, Heijnen C, Kavelaars A, Laye S, Capuron L. The neuroimmune basis of fatigue. Trends Neurosci. 2014;37(1):39-46.

Supplemental eReferences are available at links.lww.com/WNL/B607 


\section{Neurology}

\section{Frequency of Neurologic Manifestations in COVID-19: A Systematic Review and Meta-analysis}

Shubham Misra, Kavitha Kolappa, Manya Prasad, et al.

Neurology 2021;97;e2269-e2281 Published Online before print October 11, 2021

DOI 10.1212/WNL.0000000000012930

This information is current as of October 11, 2021

\section{Updated Information \&} Services

References

Citations

Subspecialty Collections

Permissions \& Licensing

Reprints including high resolution figures, can be found at: http://n.neurology.org/content/97/23/e2269.full

This article cites 29 articles, 2 of which you can access for free at: http://n.neurology.org/content/97/23/e2269.full\#ref-list-1

This article has been cited by 1 HighWire-hosted articles: http://n.neurology.org/content/97/23/e2269.full\#\#otherarticles

This article, along with others on similar topics, appears in the following collection(s):

All Cerebrovascular disease/Stroke

http://n.neurology.org/cgi/collection/all_cerebrovascular_disease_strok e

All Clinical Neurology

http://n.neurology.org/cgi/collection/all_clinical_neurology

COVID-19

http://n.neurology.org/cgi/collection/covid_19

Prevalence studies

http://n.neurology.org/cgi/collection/prevalence_studies

Viral infections

http://n.neurology.org/cgi/collection/viral_infections

Information about reproducing this article in parts (figures,tables) or in its entirety can be found online at:

http://www.neurology.org/about/about_the_journal\#permissions

Information about ordering reprints can be found online:

http://n.neurology.org/subscribers/advertise

Neurology $®$ is the official journal of the American Academy of Neurology. Published continuously since 1951, it is now a weekly with 48 issues per year. Copyright @ 2021 American Academy of Neurology. All rights reserved. Print ISSN: 0028-3878. Online ISSN: 1526-632X.

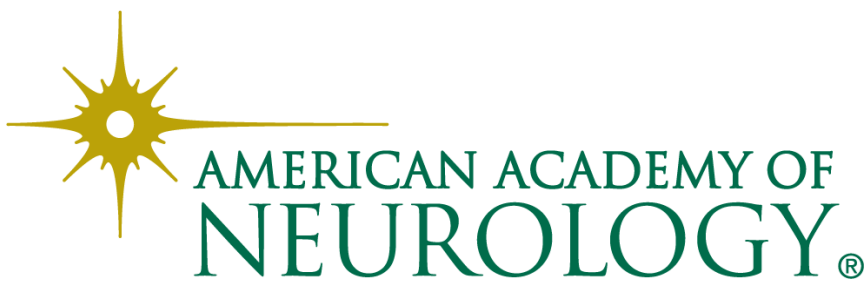

